\title{
Predictors for imaging progression on chest CT from coronavirus disease 2019 (COVID-19) patients
}

\author{
Zongguo Yang ${ }^{1,}{ }^{*}$, Jia Shi ${ }^{1,}{ }^{*}$, Zhang He ${ }^{2,}{ }^{*}$, Ying Lü ${ }^{1}$, Qingnian $\mathrm{Xu}^{1}$, Chen $\mathrm{Ye}^{1}$, Shishi Chen ${ }^{1}$, Bozong \\ Tang $^{1}$, Keshan Yin ${ }^{1}$, Yunfei Lu ${ }^{1}$, Xiaorong Chen ${ }^{1}$ \\ ${ }^{1}$ Department of Integrative Medicine, Shanghai Public Health Clinical Center, Fudan University, Shanghai 201508, \\ China \\ ${ }^{2}$ Department of Neurology, Shanghai Public Health Clinical Center, Fudan University, Shanghai 201508, China \\ *Equal contribution
}

Correspondence to: Xiaorong Chen, Yunfei Lu; email: xiaorong3chen@163.com, luyunfei78@shphc.org.cn Keywords: coronavirus disease 2019, COVID-19, monocyte-lymphocyte ratio, MLR, age

Received: February 29, $2020 \quad$ Accepted: March 28, 2020

Published: April 10, 2020

Copyright: Yang et al. This is an open-access article distributed under the terms of the Creative Commons Attribution License (CC BY 3.0), which permits unrestricted use, distribution, and reproduction in any medium, provided the original author and source are credited.

\section{ABSTRACT}

Objective: This study aimed to investigate the potential parameters associated with imaging progression on chest CT from coronavirus disease 19 (COVID-19) patients.

Results: The average age of 273 COVID-19 patients enrolled with imaging progression were older than those without imaging progression $(p=0.006)$. The white blood cells, platelets, neutrophils and acid glycoprotein were all decreased in imaging progression patients (all $p<0.05)$, and monocytes were increased $(p=0.025)$. The parameters including homocysteine, urea, creatinine and serum cystatin $C$ were significantly higher in imaging progression patients (all $p<0.05$ ), while eGFR decreased $(p<0.001)$. Monocyte-lymphocyte ratio (MLR) was significantly higher in imaging progression patients compared to that in imaging progression-free ones $(p<$ 0.001). Logistic models revealed that age, MLR, homocysteine and period from onset to admission were factors for predicting imaging progression on chest CT at first week from COVID-19 patients (all $p<0.05$ ).

Conclusion: Age, MLR, homocysteine and period from onset to admission could predict imaging progression on chest CT from COVID-19 patients.

Methods: The primary outcome was imaging progression on chest CT. Baseline parameters were collected at the first day of admission. Imaging manifestations on chest CT were followed-up at (6士1) days.

\section{INTRODUCTION}

Since the end of 2019, a novel coronavirus with personto-person transmission has spread to many other countries worldwide [1-5]. Previous epidemiology report uncovered that the epidemic of coronavirus disease 2019 (COVID-19) has doubled every 7.4 day in its early stage, with an average serial interval of 7.5 days [3]. Early information estimated that the basic reproductive number $\mathrm{R}_{0}$ was estimated to be $1.4-2.5$ reported by WHO [2]. The pandemic is accelerating at an exponential rate and at risk of escalating into a global health emergency [2]. The mortality of coronavirus disease 2019 (COVID-19) patients in China is approximately $2.3 \%$, compared with $9.6 \%$ of severe acute respiratory syndrome (SARS) and $34.4 \%$ of middle east respiratory syndrome (MERS) reported by WHO [6]. Even this virus is not as fetal as people thought, the transmissibility is far exceeding that of SARS and MERS [7]. Although many clinical and epidemiological literatures have been published [3-6, $8-10$ ], the spread in still ongoing and the early warning parameters for disease progression remain incomplete.

Compared to symptoms, chest CT findings were more rapid and frequent $[11,12]$. The imaging performance on 
chest CT scans from COVID-19 patients mainly manifested as bilateral ground-glass opacities (GGOs) in the lung periphery [13]. In a retrospective cohort, chest CTs of 121 symptomatic COVID-19 patients have been reviewed. Bilateral lung involvement was observed in $10 / 36$ early patients (28\%), 25/33 intermediate patients (76\%), and 22/25 late patients (88\%) [11]. Currently, chest CT is used to assess the severity of lung involvement in COVID-19 pneumonia [14]. In a cohort study, $85.7 \%$ (54/63) confirmed COVID-19 patients developed imaging progression including enlarged and increased extent of GGOs and consolidation at early follow-up chest CT scans [12]. That is, short-term imaging progression on chest CT from COVID-19 patients should be early predicted and intervened.

In this analysis, we summarized the baseline characteristics and investigated the potential predictive parameters for imaging progression on chest CT scans at first week after admission of COVID-19 patients, in the hope that the data may provide novel biomarker candidates as well as useful insights into the pathogenesis and progression of COVID-19 patients.

\section{RESULTS}

Imaging performance of progression and progression-free patients

As shown in Figure 1, most mild type COVID-19 patients had bilateral and peripheral GGOs, consolidation and linear opacities imaging involvements on chest $\mathrm{CT}$ at the first admission day. Some patients had no remarkable hallmarks. At the first six $( \pm 1)$ day, enlarged and increased GGOs, consolidation, solid nodules and fibrous stripes were observed for patients suffered from imaging progression on chest CT scans. On the contrary, the GGOs, consolidation and linear opacities were partly resolved and decreased for imaging progression-free patients.
A

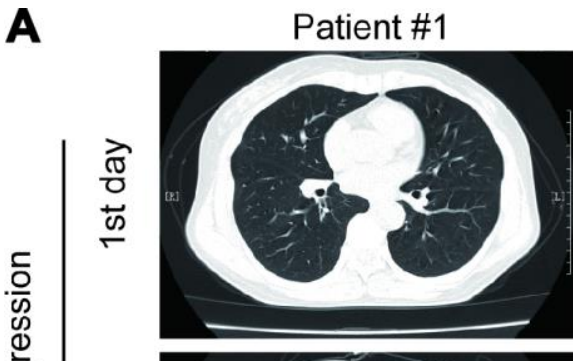

은

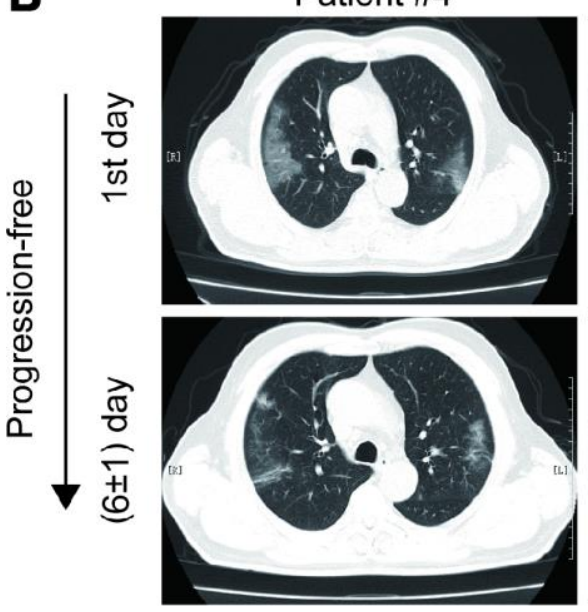

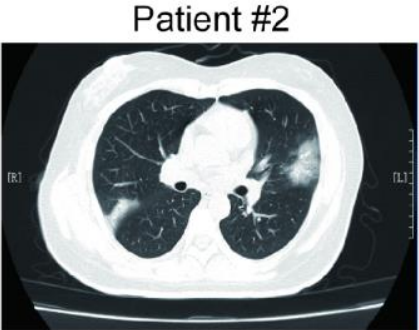

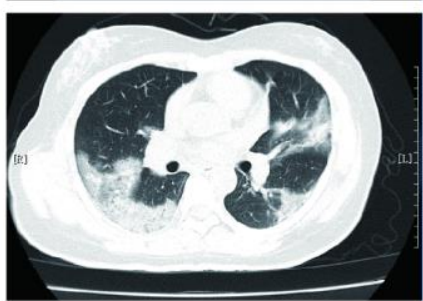

Patient \#5
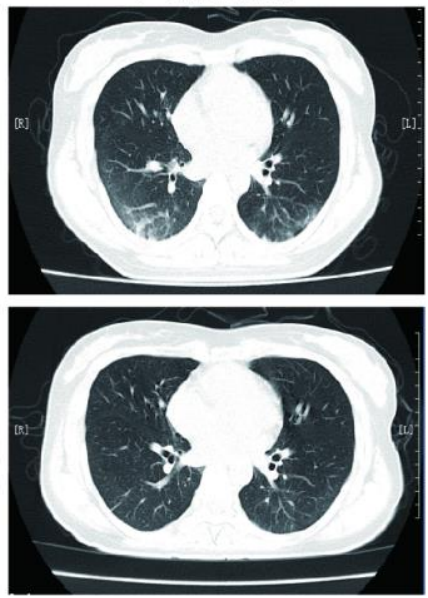

Patient \#3
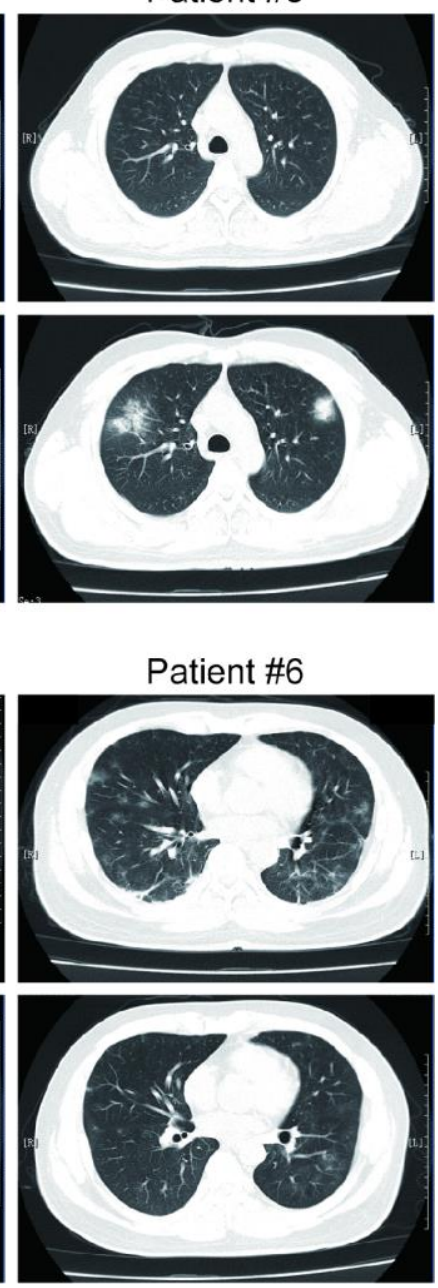

Figure 1. Examples of imaging progression (A) and progression-free (B) in chest CT from COVID-19 patients. 


\section{Baseline characteristics and inflammatory model comparisons between imaging progression and progression-free patients}

In total, 71 COVID-19 patients suffered from imaging progression on chest CT at first week after admission, and the other 202 patients were imaging progressionfree on chest CT. As summarized in Table 1, the patients in imaging progression group were significantly older than those in imaging progressionfree group $(p=0.006$, Table 1$)$. More patients were treated with gamma globulin and thymosin in imaging progression group compared to those without imaging progression $(p=0.022$ and $p=0.001$, respectively, Table 1). In blood routine tests, the white blood cells (WBC), platelets and neutrophils were significantly lower in imaging progression patients than those in imaging progression-free ones $(\mathrm{p}=0.025, \mathrm{p}=0.044$ and $\mathrm{p}=0.014$, respectively, Table 1 ), while the monocytes were significantly higher in imaging progression patients $(\mathrm{p}=0.025$, Table 1). Additionally, acid glycoprotein was significantly lower in imaging progression patients $(\mathrm{p}=0.037$, Table 1). In liver function tests, gamma-glutamyl transferase (GGT) levels were significantly higher in imaging progression-free patients $(\mathrm{p}=0.045$, Table 1), while homocysteine levels were significantly higher in imaging progression patients $(\mathrm{p}=0.006$, Table1). In kidney function tests, urea, creatinine and serum cystatin $\mathrm{C}$ levels were significantly higher in imaging progression patients compared to those in imaging progression-free ones $(\mathrm{p}=0.011, \mathrm{p}=0.007$, respectively, Table 1). As we expected, the estimated glomerular filtration rate (eGFR) levels were significantly decreased in imaging progression patients $(\mathrm{p}<0.001$, Table 1$)$. No differences were found in cardiac markers and coagulation function tests.

Six inflammatory models were compared between imaging progression and progression-free patients. As shown in Figure 2, monocyte-lymphocyte ratio (MLR) levels were significantly higher in imaging progression patients than those in imaging progression-free ones ( $p$ $<0.001$, Figure 2C), while no differences were found among aspartate aminotransferase-lymphocyte ratio index (ALRI), aspartate aminotransferase-platelet ratio index (APRI), neutrophil-lymphocyte ratio (NLR), platelet-lymphocyte ratio (PLR) and systemic immuneinflammation index (SII) between these two groups (Figure 2A, 2B, 2D-2F).

\section{Co-manifestations on chest CT and outcomes}

As summarized in Table 2, except for common manifestations on chest $\mathrm{CT}$, chronic inflammatory manifestation, chronic bronchitis / emphysema, pericardial effusion, pleural effusion, bullae of lung and obsolete tuberculosis were the most frequent imaging co-manifestations in COVID-19 patients. COVID-19 patients with imaging progression had significantly higher frequency of chronic inflammatory manifestation than those without imaging progression $(12.7 \%$ vs. $3.5 \%, \mathrm{p}=0.005$, Table 2). No differences were found in distributions of chronic bronchitis / emphysema, pericardial effusion, pleural effusion, bullae of lung and obsolete tuberculosis between these two groups (Table 2).

Moreover, no acute bacterial or other viral co-infection performances on chest CT were found in these COVID19 patients.

All these COVID-19 patients did not develop severe conditions, no one died during our follow up.

\section{Parameters associated with imaging progression on chest CT}

Variables including age, gender, disease history, epidemiology, chest CT imaging, therapeutic strategies, period from onset to admission, ALRI, APRI, MLR, NLR, PLR, SII, WBC, neutrophils, lymphocytes, monocytes, platelet, red blood cells (RBC), hemoglobin, C-reactive protein (CRP), erythrocyte sedimentation rate (ESR), procalcitonin, alanine aminotransferase (ALT), aspartate aminotransferase (AST), GGT, lactate dehydrogenase (LDH), total bilirubin (TBiL), albumin, globulin, urea, creatinine, eGFR, lactic acid, haptoglobin, acid glycoprotein, cystatin $\mathrm{C}$, homocysteine, retinolbinding protein, cardiac troponin (cTnI), myoglobin, brain natriuretic peptide prohormone (pro-BNP), prothrombin time, prothrombin activity (PTA), international normalized ratio (INR), D-dimer were included in the univariate analysis. As presented in Table 3, age, gamma globulin therapy, thymosin therapy, MLR, serum cystatin C, homocysteine, eGFR and period from onset to admission were potential parameters associated with imaging progression (all $\mathrm{p}$ $<0.05$, Table 3). When these parameters were included in the multivariate model, age, MLR and homocysteine were significantly correlated with imaging progression on chest CT from COVID-19 patients $(\mathrm{RR}=2.28,95 \% \mathrm{CI}=1.12-4.34, \mathrm{p}=0.012$; $\mathrm{RR}=7.69,95 \% \mathrm{CI}=1.67-35.55, \mathrm{p}=0.009$ and $\mathrm{RR}=$ $3.17,95 \% \mathrm{CI}=1.01-9.96, \mathrm{p}=0.048$; respectively, Table 3). In addition, COVID-19 patients with period from onset to admission $\geq 4$ days might have lower risk to develop imaging progression on chest $\mathrm{CT}$ at first week after admission $(\mathrm{RR}=0.35,95 \% \mathrm{CI}=0.19-$ $0.67, \mathrm{p}=0.001$, Table 3). 
Table 1. Baseline characteristics of COVID-19 patients.

\begin{tabular}{|c|c|c|c|}
\hline \multirow[b]{2}{*}{ Variables } & \multicolumn{2}{|c|}{ Chest CT } & \multirow[b]{2}{*}{$p$ value } \\
\hline & $\begin{array}{c}\text { Progression group } \\
(\mathrm{n}=71)\end{array}$ & $\begin{array}{c}\text { Progression-free group } \\
(n=202)\end{array}$ & \\
\hline Age, years, mean $\pm S D$ & $53.5 \pm 1.9$ & $47.6 \pm 1.1$ & 0.006 \\
\hline Male, n (\%) & $33(46.5)$ & $101(50)$ & 0.61 \\
\hline Disease history, n (\%) & & & 0.614 \\
\hline None & $48(67.6)$ & $143(70.8)$ & \\
\hline Hypertension & $13(18.3)$ & $27(13.4)$ & \\
\hline Diabetes & $7(9.9)$ & $11(5.4)$ & \\
\hline Fatty liver disease & $12(16.9)$ & $27(13.4)$ & \\
\hline Others & $3(4.2)$ & $21(10.4)$ & \\
\hline \multicolumn{4}{|l|}{ Epidemiology, n (\%) } \\
\hline Hubei sojourning history & $43(56.3)$ & $108(53.5)$ & 0.301 \\
\hline Contact with COVID-19 patients & $27(38.0)$ & $72(35.6)$ & 0.719 \\
\hline \multicolumn{4}{|l|}{ Therapeutic strategy, n (\%) } \\
\hline Antivirus drugs & $58(81.7)$ & $141(69.8)$ & 0.053 \\
\hline Antibiotics & $22(31.0)$ & $46(22.8)$ & 0.169 \\
\hline Gamma globulin & $13(18.3)$ & $17(8.4)$ & 0.022 \\
\hline Thymosin & $20(28.2)$ & $23(11.4)$ & 0.001 \\
\hline Glucocorticoid & $10(14.1)$ & $17(8.4)$ & 0.169 \\
\hline TCM decoction & $5(7.0)$ & $25(12.4)$ & 0.216 \\
\hline TCM patent & $27(38.0)$ & $58(28.7)$ & 0.145 \\
\hline Chest CT imaging, n (\%) & & & 0.504 \\
\hline Bilateral lung lesion & $60(84.5)$ & 177 (87.6) & \\
\hline Single lung lesion & $11(15.5)$ & $25(12.4)$ & \\
\hline \multicolumn{4}{|l|}{ Blood routine tests, mean $\pm \mathrm{SD}$} \\
\hline $\mathrm{WBC}, 10^{3} / \mathrm{mm}^{3}$ & $4.6 \pm 0.1$ & $5.2 \pm 0.1$ & 0.025 \\
\hline $\mathrm{RBC}, 10^{4} / \mathrm{mm}^{3}$ & $4.4 \pm 0.1$ & $4.5 \pm 0.04$ & 0.334 \\
\hline Hemoglobin, g/L & $135.1 \pm 1.7$ & $136.7 \pm 1.1$ & 0.465 \\
\hline Platelet, $10^{3} / \mathrm{mm}^{3}$ & $176.0 \pm 6.6$ & $195.0 \pm 5.1$ & 0.044 \\
\hline Neutrophils, $10^{3} / \mathrm{mm}^{3}$ & $2.9 \pm 0.1$ & $3.5 \pm 0.1$ & 0.014 \\
\hline Lymphocytes, $10^{3} / \mathrm{mm}^{3}$ & $1.2 \pm 0.1$ & $1.3 \pm 0.04$ & 0.342 \\
\hline Monocytes, $10^{3} / \mathrm{mm}^{3}$ & $0.5 \pm 0.03$ & $0.4 \pm 0.01$ & 0.025 \\
\hline Hypersensitive CRP, mg/L, mean \pm SD & $17.5 \pm 2.4$ & $18.7 \pm 1.6$ & 0.697 \\
\hline ESR, mm/Hour, mean \pm SD & $56.9 \pm 4.3$ & $64.5 \pm 2.7$ & 0.148 \\
\hline Procalcitonin, ng/ml, mean \pm SD & $0.05 \pm 0.01$ & $0.09 \pm 0.05$ & 0.687 \\
\hline Acid glycoprotein, $\mathrm{mg} / \mathrm{dl}$, mean $\pm \mathrm{SD}$ & $140.9 \pm 5.6$ & $154.5 \pm 3.3$ & 0.037 \\
\hline \multicolumn{4}{|l|}{ Liver function tests, mean $\pm \mathrm{SD}$} \\
\hline ALT, U/L & $27.6 \pm 2.3$ & $27.6 \pm 1.4$ & 0.995 \\
\hline AST, U/L & $29.4 \pm 1.7$ & $29.2 \pm 1.6$ & 0.958 \\
\hline GGT, U/L & $29.5 \pm 2.5$ & $38.6 \pm 2.5$ & 0.045 \\
\hline LDH, U/L & $244.4 \pm 10.4$ & $248.8 \pm 5.8$ & 0.703 \\
\hline TBiL, $\mu \mathrm{mol} / \mathrm{L}$ & $8.4 \pm 0.4$ & $9.2 \pm 0.3$ & 0.116 \\
\hline Albumin, g/L & $40.8 \pm 0.4$ & $41.1 \pm 0.3$ & 0.537 \\
\hline Globulin, g/L & $28.8 \pm 0.5$ & $29.0 \pm 0.3$ & 0.693 \\
\hline Homocysteine, $\mu \mathrm{mol} / \mathrm{L}$ & $10.7 \pm 0.5$ & $9.3 \pm 0.2$ & 0.006 \\
\hline \multicolumn{4}{|l|}{ Renal function test, mean $\pm \mathrm{SD}$} \\
\hline Urea, mmol/L & $5.1 \pm 0.2$ & $4.5 \pm 0.1$ & 0.011 \\
\hline Creatinine, $\mu \mathrm{mol} / \mathrm{L}$ & $70.7 \pm 3.0$ & $63.0 \pm 1.3$ & 0.007 \\
\hline Serum cystatin $\mathrm{C}, \mathrm{mg} / \mathrm{L}$ & $1.0 \pm 0.04$ & $0.8 \pm 0.01$ & $<0.001$ \\
\hline eGFR, $\mathrm{ml} /\left(\min \times 1.73 \mathrm{~m}^{2}\right)$ & $101.3 \pm 3.1$ & $116.3 \pm 1.9$ & $<0.001$ \\
\hline Lactic acid, $\mathrm{mmol} / \mathrm{L}$, mean $\pm \mathrm{SD}$ & $2.8 \pm 0.1$ & $2.8 \pm 0.04$ & 0.936 \\
\hline Haptoglobin, mg/dl, mean \pm SD & $209.2 \pm 12.0$ & $229.6 \pm 7.0$ & 0.142 \\
\hline Retinol-binding protein, $\mathrm{mg} / \mathrm{L}$, mean $\pm \mathrm{SD}$ & $27.8 \pm 1.4$ & $26.4 \pm 0.7$ & 0.327 \\
\hline Cardiac markers, mean \pm SD & & & \\
\hline
\end{tabular}


cTnI, ng/ml

Myoglobin, ng/ml

Pro-BNP, pg/ml

Coagulation function tests, mean \pm SD

INR

PTA

Prothrombin time, second

D-Dimer, $\mu \mathrm{g} / \mathrm{ml}$

$$
\begin{gathered}
0.029 \pm 0.004 \\
17.5 \pm 3.0 \\
73.5 \pm 13.7 \\
1.01 \pm 0.008 \\
99.9 \pm 1.2 \\
13.4 \pm 0.08 \\
0.55 \pm 0.06
\end{gathered}
$$

TCM, Traditional Chinese Medicine; WBC, white blood cells; RBC, red blood cells; CRP, C-reactive protein; ESR, erythrocyte sedimentation rate; ALT, alanine aminotransferase; AST, aspartate aminotransferase; GGT, gamma-glutamyl transferase; LDH, lactate dehydrogenase; TBiL, total bilirubin; eGFR, estimated glomerular filtration rate; cTnl, cardiac troponin; Pro-BNP, Brain natriuretic peptide prohormone; INR, international normalized ratio; PTA, prothrombin activity.

\section{Predictive values of MLR and age for imaging progression on chest $\mathrm{CT}$}

Using OptimalCutpoints package in $\mathrm{R}$ program, we detected that the optimal cutoff of MLR was 0.51 . The sensitivity, specificity, positive predictive value (PPV) and negative predictive value (NPV) of MLR for predicting imaging progression on chest CT were 0.44 ,
$0.79,0.42$ and 0.80 , respectively (Figure $3 \mathrm{~A}$ and Table 4). And, the AUC of MLR for predicting imaging progression on chest CT was 0.63 (Figure 3A).

The optimal cutoff of age for predicting imaging progression on chest CT was 51 years. The sensitivity, specificity, PPV and NPV were $0.65,0.58,0.35$ and 0.83 respectively (Figure $3 \mathrm{~B}$ and Table 4 ). ROC curve
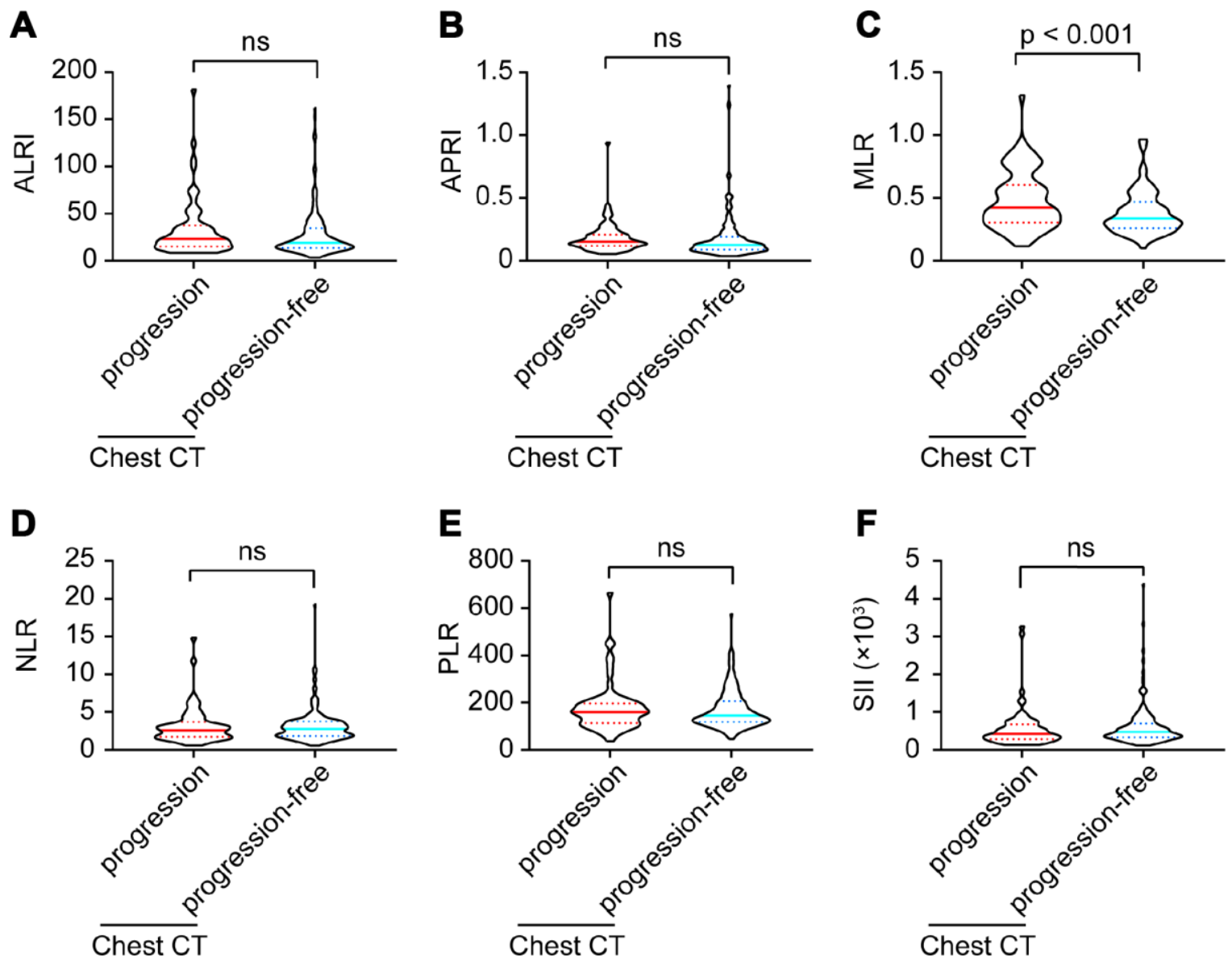

Figure 2. ALRI (A), APRI (B), MLR (C), NLR (D), PLR (E) and SII (F) model comparisons between imaging progression and progression-free COVID-19 patients. 
Table 2. Co-manifestations on chest CT in COVID-19 patients.

\begin{tabular}{lccc}
\hline & \multicolumn{2}{c}{ Chest CT } & P value \\
\cline { 2 - 3 } Co-manifestations, $\mathbf{n}(\boldsymbol{\%})$ & $\begin{array}{c}\text { Progression group } \\
(\mathbf{n}=\mathbf{7 1})\end{array}$ & $\begin{array}{c}\text { Progression-free group } \\
(\mathbf{n}=\mathbf{2 0 2})\end{array}$ & p \\
\hline Chronic inflammatory manifestations & $9(12.7)$ & $7(3.5)$ & 0.005 \\
Chronic bronchitis / emphysema & $2(2.8)$ & $2(1.0)$ & 0.271 \\
Pericardial effusion & $1(1.4)$ & $1(0.5)$ & 0.438 \\
Pleural effusion & $1(1.4)$ & $0(0)$ & 0.091 \\
Bullae of lung & $1(1.4)$ & $2(1.0)$ & 0.771 \\
Obsolete tuberculosis & $2(2.8)$ & $1(0.5)$ & 0.107 \\
\hline
\end{tabular}

Table 3. parameters associated with imaging progression in chest CT from COVID-19 patients".

\begin{tabular}{|c|c|c|c|c|c|c|}
\hline \multirow{2}{*}{ Variables } & \multicolumn{2}{|c|}{ Univariate } & \multirow{2}{*}{$p$ value } & \multicolumn{2}{|c|}{ Multivariate } & \multirow{2}{*}{ p value } \\
\hline & RR & $95 \% \mathrm{CI}$ & & $\mathbf{R R}$ & $95 \% \mathrm{CI}$ & \\
\hline \multicolumn{7}{|l|}{ Age, years } \\
\hline$<60$ & reference & - & 1.0 & reference & - & 1.0 \\
\hline$\geq 60$ & 2.72 & $1.55-4.78$ & $<0.001$ & 2.28 & $1.12-4.34$ & 0.012 \\
\hline Gamma globulin, yes vs. no & 2.44 & $1.12-5.32$ & 0.025 & 1.08 & $0.38-3.08$ & 0.89 \\
\hline Thymosin, yes vs. no & 3.05 & $1.55-6.0$ & 0.001 & 2.32 & $0.94-5.73$ & 0.069 \\
\hline MLR, per increase 1 unit & 12.2 & $3.09-48.23$ & $<0.001$ & 7.69 & $1.67-35.55$ & 0.009 \\
\hline \multicolumn{7}{|l|}{ Serum cystatin $\mathrm{C}, \mathrm{mg} / \mathrm{L}$} \\
\hline$<1.03$ & reference & - & 1.0 & reference & - & 1.0 \\
\hline$>1.03$ & 2.8 & $1.35-5.82$ & 0.006 & 0.79 & $0.28-2.2$ & 0.65 \\
\hline \multicolumn{7}{|l|}{ Homocysteine, $\mu \mathrm{mol} / \mathrm{L}$} \\
\hline$<15.4$ & reference & - & 1.0 & reference & - & 1.0 \\
\hline$>15.4$ & 3.54 & $1.23-10.14$ & 0.019 & 3.17 & $1.01-9.96$ & 0.048 \\
\hline \multicolumn{7}{|l|}{$\mathrm{eGFR}, \mathrm{ml} /\left(\min \times 1.73 \mathrm{~m}^{2}\right)$} \\
\hline$>90$ & reference & - & 1.0 & reference & - & 1.0 \\
\hline$<90$ & 2.97 & $1.54-5.75$ & 0.001 & 1.63 & $0.67-4.0$ & 0.281 \\
\hline \multicolumn{7}{|c|}{ Period from onset to admission, days } \\
\hline$<4$ & reference & - & 1.0 & reference & - & 1.0 \\
\hline$\geq 4$ & 0.36 & $0.20-0.64$ & 0.001 & 0.35 & $0.19-0.67$ & 0.001 \\
\hline
\end{tabular}

Variables including age, gender, disease history, epidemiology, chronic inflammatory co-manifestation on chest $\mathrm{CT}$, therapeutic strategies, period from onset to admission, ALRI, APRI, MLR, NLR, PLR, SII, WBC, neutrophils, lymphocytes, monocytes, platelet, RBC, hemoglobin, CRP, ESR, procalcitonin, ALT, AST, GGT, LDH, TBiL, albumin, globulin, urea, creatinine, eGFR, lactic acid, haptoglobin, acid glycoprotein, cystatin C, homocysteine, retinol-binding protein, cTnl, myoglobin, pro-BNP, prothrombin time, PTA, INR, D-dimer were included in the univariate analysis. Only variables with $p<0.05$ in univariate model were included in the multivariate analysis. \# Only variables significantly associated with imaging progression in chest CT in univariate analysis were presented.

revealed that the AUC of age in the prediction model was 0.6 (Figure 3B).

In addition, the optimal cutoff of homocysteine for predicting imaging progression on chest CT from COVID-19 patients was $10.58 \mu \mathrm{mol} / \mathrm{L}$. The sensitivity, specificity, PPV and NPV were 0.42, 0.79, 0.41 and 0.80 , respectively (Figure $3 \mathrm{C}$ and Table 4 ).

We performed ROC comparison in MLR, age and homocysteine using ROC regression. As showed in Figure 3D, no difference among these three indexes was found $(p=0.834$, Figure 3D).

\section{DISCUSSION}

According to the Chinese guidelines, imaging progression-free on chest CT scans was one of discharge criteria for COVID-19 patients. At present stage, the long-term imaging features of COVID-19 are not yet known $[13,15]$. Follow-up imaging in COVID19 patients often demonstrated the disease progression. Generally, imaging manifestations are in line with the severity of COVID-19 [16]. Hence, a short-term follow up with identification of imaging progression is of great importance for early warning of disease aggravation from COVID-19 patients, which could help clinicians to 
manage quickly and accurately [12]. Considered that, we defined the imaging progression at first week on chest $\mathrm{CT}$ as the primary outcome.

In this outbreak, age was considered as one critical content during the disease occurrence and development. Our results also revealed that the average age of patients with imaging progression was older than those without. Logistic model confirmed that age should be a risk factor for predicting imaging progression. Previous reports suggested that COVID-19 is more susceptible to infect older adults [3, 8, 10]. Research with small samples of $2019-\mathrm{nCoV}$ infected infants have been reported [17]. In a study included 34 COVID-19

A MLR

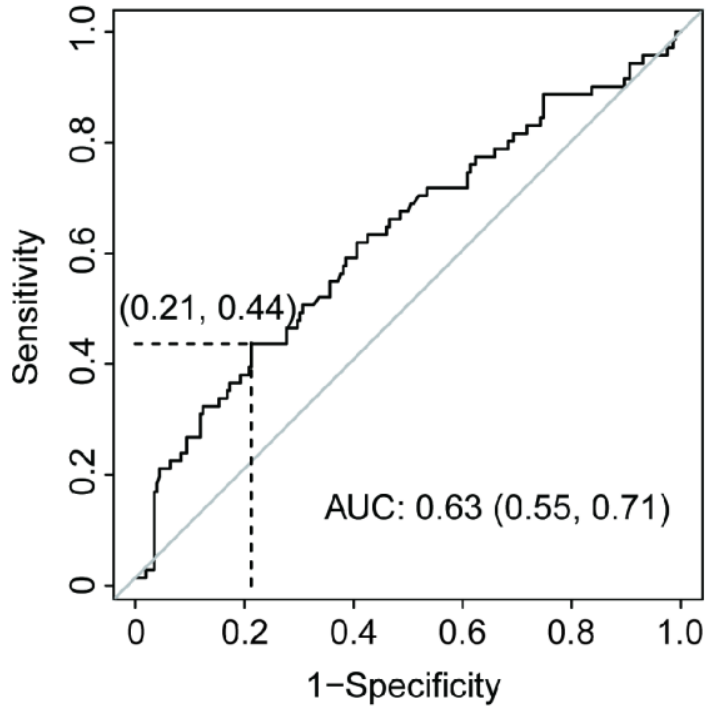

C Homocysteine

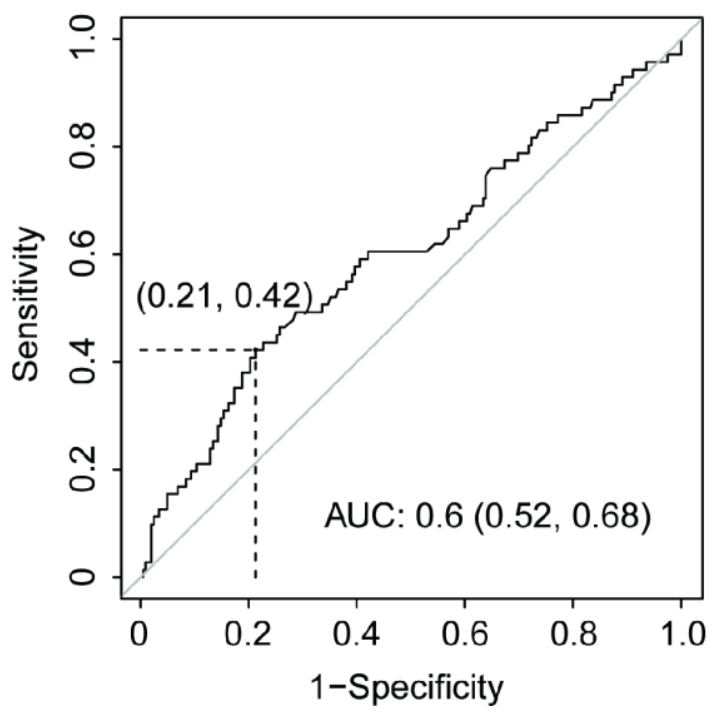

children, the authors concluded that the clinical manifestations in children with 2019-nCoV infection are non-specific and are milder than that in adults [18]. In a nationwide retrospective study, 2143 pediatric patients were included. They found that more than $90 \%$ patients were asymptomatic, mild, or moderate, even though young children, particularly infants, were vulnerable to infection [19]. The first deaths of COVID19 occurred frequently among elderly people, who may progress more faster [20]. In a multicenter cohort study with 137 patients enrolled, age was shown to be associated with high risk of death in COVID-19 patients. Middle-aged and elderly patients with underlying comorbidities are prone to respiratory failure

B Age

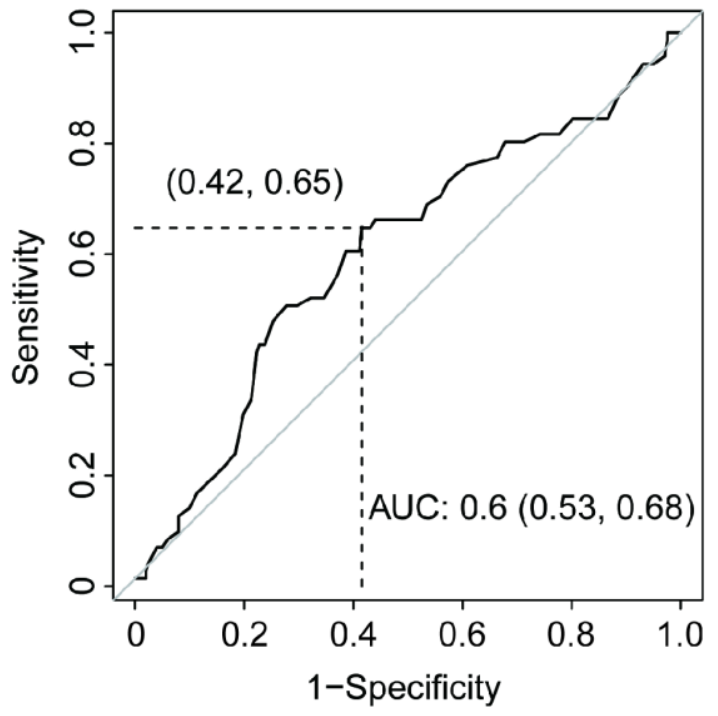

D ROC comparison

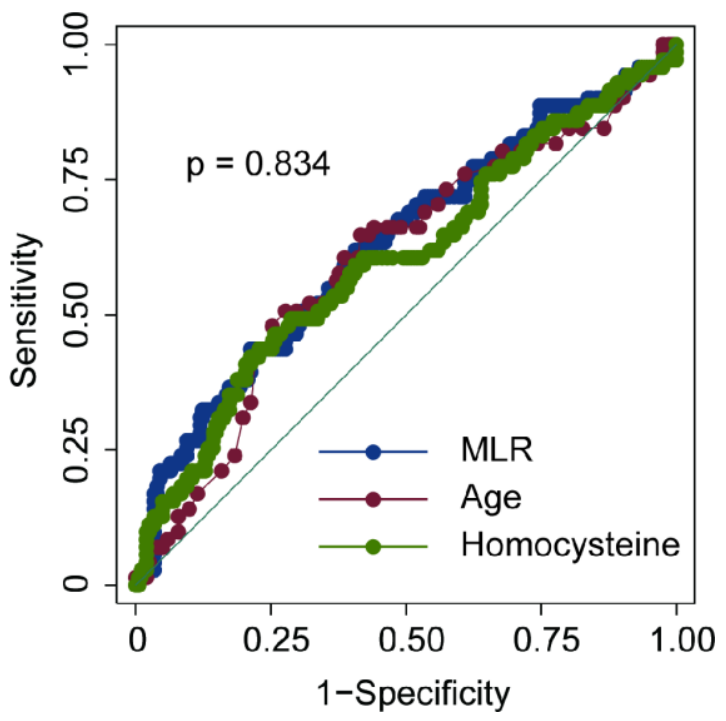

Figure 3. ROC of MLR (A), age (B), homocysteine (C) and ROC comparison (D) for imaging progression in chest CT from COVID-19 patients. 
Table 4. Predictive values of MLR model, age and homocysteine for imaging progression on chest CT from COVID-19 patients.

\begin{tabular}{lcc}
\hline & Estimate & $\mathbf{9 5 \%}$ CI \\
\hline MLR & & - \\
Cutoff & 0.51 & $0.32-0.56$ \\
Sensitivity & 0.44 & $0.72-0.84$ \\
Specificity & 0.79 & $0.34-0.54$ \\
Positive predictive value & 0.42 & $0.71-0.85$ \\
Negative predictive value & 0.80 & - \\
Age, years & & $0.53-0.76$ \\
Cutoff & 51 & $0.51-0.65$ \\
Sensitivity & 0.65 & $0.29-0.48$ \\
Specificity & 0.58 & $0.74-0.86$ \\
Positive predictive value & 0.35 & \\
Negative predictive value & 0.83 & \\
Homocysteine, $\mu$ mol/L & & $0.31-0.55$ \\
Cut off & 10.58 & $0.72-0.84$ \\
Sensitivity & 0.42 & $0.33-0.53$ \\
Specificity & 0.79 & $0.70-0.85$ \\
Positive predictive value & 0.41 & 0.80 \\
Negative predictive value & 0.80 \\
\hline
\end{tabular}

and have a poorer prognosis $[21,22]$. Combined the previous literatures and our results, we assumed that age also should be a risk factor for imaging progression at the early stage of COVID-19.

Among the six inflammatory models, MLR was significantly higher in COVID-19 patients with imaging progression on chest CT scans, and correlated with imaging aggravation. Previous evidence demonstrated that monocytes/macrophages were susceptible to human coronavirus $(\mathrm{HCoV}) 229 \mathrm{E}$ infection, but strongly restricted OC43 replication [23]. Differs from $\mathrm{HCoV}$ 229E, SARS-CoV poorly infects human purified monocytes/macrophages, and production of interferonalpha by these cells further limits the infection [24]. Following infection of monocytes/macrophages by HCoV-OC43, viability remained high over 6 days and no apoptosis was observed [25]. These clues suggested that monocytes might be stable in function and quantity levels during $\mathrm{HCoV}$ infection like SARS and 2019-CoV. Conversely, SARS-CoV frequently targets for cytotoxic $\mathrm{T}$ lymphocytes [26, 27]. Lymphopenia is one of hematological abnormalities during SARS-CoV infection, and lymphocyte counts could predict the severity and clinical outcomes [28]. Previous study showed that lymphocytes and its subsets significantly decreased in SARS patients, while those with severe clinical illness or those who died had more remarkable CD4+ and CD8+ lymphopenia [28]. Also, MERS-CoV could efficiently infected $\mathrm{T}$ lymphocytes from the peripheral blood and from human lymphoid organs and induced apoptosis in T lymphocytes [29]. Similar with SARS-CoV and MERS-CoV, 2019-nCoV infection also related with loss of lymphocytes, which was supported by Chinese guidelines [30, 31]. Thus, the MLR increased especially in patients with disease progression.

Homocysteine is a potent toxic agent that involved in oxidative stress and neurotoxicity promotion, endothelial dysfunction, and acceleration of the atherosclerotic process [32-34]. Emerging evidences revealed that hyperhomocysteinemia contributed to a spectrum of disease development, including cardiovascular disease, diabetes, chronic kidney disease and fatty liver disease [35-37]. Previous reports uncovered that homocysteine concentrations were greater in many virus infections including human immunodeficiency virus, hepatitis virus and human papilloma virus [38-40]. However, the roles of homocysteine in coronavirus infection have not been well illustrated. Based on our results, homocysteine concentrated in imaging progression patients and showed predictive value for imaging progression.

Our results also demonstrated that COVID-19 patients with period from onset to admission $\geq 4$ days had lower risk to develop imaging progression on chest $\mathrm{CT}$ at first week after admission. On the one hand, patients with 
period over 4 days might have mild clinical symptoms, which in line with mild or slow progression of this disease. On the other hand, the period from onset to admission should be counted in the natural process of 2019-nCoV infection.

This study has some limitations. First, only mild type of COVID-19 patients was included, and severe type and life-threating types were excluded in this analysis. Second, MLR and age did not have powerful prognostic values for imaging progression on chest $\mathrm{CT}$ in our study. Therefore, we suggest that they be used in combination in clinical practice. Third, the follow-up period was short-term, more solid outcomes should be considered in future. And, subgroup analysis of category manifestation of imaging progression on chest CT should also be considered. Even though, age, MLR model, homocysteine and period from onset to admission might be useful for evaluating disease progression in COVID-19 patients.

\section{MATERIALS AND METHODS}

\section{Ethic statement}

All participants provided written informed consent during their admission. The study protocol and informed consent documents were reviewed and approved by the Ethics Committee of Shanghai Public Health Clinical Center, Fudan University.

\section{Patients}

In accordance to the $4^{\text {th }}$ edition of "Diagnosis and management program of novel coronavirus-infected pneumonia" released by National Health Commission of The People's Republic of China [30], 273 diagnosed COVID-19 patients with mild category in Shanghai Public Health Clinical Center were included in this analysis. 2019 novel coronavirus (2019-nCoV) nucleic acid of sputum samples from all participants were positive detected by real-time polymerase chain reaction. The influenza A and B antigens of all participants were negative. All participants had no other lymphatic system disorders or malignant hematologic diseases, ensuring that the whole blood parameters were representative of normal baseline values. Patients with renal and/or hepatic failure, acute coronary syndromes, valvular heart diseases, autoimmune thyroid diseases, or systematic inflammatory diseases were excluded from our study.

\section{Study design}

This was a prospective single-center cohort study. The baseline characteristics, including demographics, treatment strategies, routine blood tests, liver-kidney function parameters, coagulation function tests, cardiac markers and chest $\mathrm{CT}$ imaging, were all collected at the first admission day. Chest CT imaging were also performed at the $(7 \pm 2)$ day during their admission. All the tests and examines were conducted in the Department of Medical Laboratory and the Department of Radiology in Shanghai Public Health Clinical Center, Fudan University.

\section{Definition}

The primary outcome was defined as imaging progression on chest CT at first week. Any one of the following criteria was considered as imaging progression on chest CT: 1) Increased ground-glass lesions in the underlying involvements; 2) Newly occurred lesions beyond underlying involvements. The chest CT imaging performance was diagnosed by two radiologists independently and inconsistency was discussed and determined by the director of Department of Radiology who acted as an arbiter.

Six inflammatory models, including ALRI, APRI, MLR, NLR, PLR and SII were included in this analysis. The definitions of these models are as follows: ALRI = AST $/ \mathrm{L} ; \mathrm{APRI}=\mathrm{AST} / \mathrm{P} ; \mathrm{MLR}=\mathrm{M} / \mathrm{L} ; \mathrm{NLR}=\mathrm{N} / \mathrm{L}$; $\mathrm{PLR}=\mathrm{P} / \mathrm{L}$; and $\mathrm{SII}=\mathrm{P} \times \mathrm{N} / \mathrm{L}$, where $\mathrm{M}, \mathrm{L}, \mathrm{N}$ and $\mathrm{P}$ are the peripheral monocyte, lymphocyte, neutrophil and platelet counts, respectively.

\section{Statistical analysis}

Differences of variables between the individual groups were analyzed using student t test and Chi-square test based on variables types. Parameters associated with the outcome were assessed by univariate and multivariate logistic regression. Only variables significantly associated with the outcome at univariate analysis (twosided $\mathrm{p}<0.05)$ included in the multivariate model. Results were reported as risk ratios (RR) with 95\% confidence intervals (CI). OptimalCutpoints package [41] in R program was used to perform ROC analysis to evaluate predictive values of potential factors for the outcome. Stata software version 16.0 (Stata Corp LLC, Texas, USA) was used for other statistics. A two-tailed $\mathrm{p}<0.05$ were considered significant for all tests.

\section{CONFLICTS OF INTEREST}

The authors have declared that no Conflicts of interest exist.

\section{FUNDING}

This work was mainly supported by National Science and Technology Major Program (2017ZX10305501) 
and Grants from Shanghai Municipal Health Commission (2020NCP001 and 2018LQ014). All the sponsors or funders play no roles in the study design, data collection and analysis, decision to publish, or preparation of the manuscript.

\section{REFERENCES}

1. Chan JF, Yuan S, Kok KH, To KK, Chu H, Yang J, Xing F, Liu J, Yip CC, Poon RW, Tsoi HW, Lo SK, Chan KH, et al. A familial cluster of pneumonia associated with the 2019 novel coronavirus indicating person-to-person transmission: a study of a family cluster. Lancet. 2020; 395:514-23.

https://doi.org/10.1016/S0140-6736(20)30154-9 PMID:31986261

2. Cheng ZJ, Shan J. 2019 Novel coronavirus: where we are and what we know. Infection. 2020; 48:155-163. https://doi.org/10.1007/s15010-020-01401-y PMID: 32072569

3. Li $Q$, Guan $X$, Wu $P$, Wang $X$, Zhou L, Tong $Y$, Ren $R$, Leung KS, Lau EH, Wong JY, Xing X, Xiang N, Wu Y, et al. Early Transmission Dynamics in Wuhan, China, of Novel Coronavirus-Infected Pneumonia. N Engl J Med. 2020; 382:1199-207.

https://doi.org/10.1056/NEJMoa2001316

PMID:31995857

4. Phan LT, Nguyen TV, Luong QC, Nguyen TV, Nguyen $H T$, Le HQ, Nguyen TT, Cao TM, Pham QD. Importation and Human-to-Human Transmission of a Novel Coronavirus in Vietnam. N Engl J Med. 2020; 382:872-74.

https://doi.org/10.1056/NEJMc2001272 PMID:31991079

5. Zhu N, Zhang D, Wang W, Li X, Yang B, Song J, Zhao X, Huang B, Shi W, Lu R, Niu P, Zhan F, Ma X, et al, and China Novel Coronavirus Investigating and Research Team. A Novel Coronavirus from Patients with Pneumonia in China, 2019. N Engl J Med. 2020; 382:727-33.

https://doi.org/10.1056/NEJMoa2001017 PMID:31978945

6. She J, Jiang J, Ye L, Hu L, Bai C, Song Y. 2019 novel coronavirus of pneumonia in Wuhan, China: emerging attack and management strategies. Clin Transl Med. 2020; 9:19.

https://doi.org/10.1186/s40169-020-00271-z PMID:32078069

7. Liu Y, Gayle AA, Wilder-Smith A, Rocklöv J. The reproductive number of COVID-19 is higher compared to SARS coronavirus. J Travel Med. 2020; 27:taaa021. https://doi.org/10.1093/itm/taaa021 PMID:32052846
8. Chen N, Zhou M, Dong X, Qu J, Gong F, Han Y, Qiu Y, Wang J, Liu Y, Wei Y, Xia J, Yu T, Zhang X, Zhang L. Epidemiological and clinical characteristics of 99 cases of 2019 novel coronavirus pneumonia in Wuhan, China: a descriptive study. Lancet. 2020; 395:507-13. https://doi.org/10.1016/S0140-6736(20)30211-7 PMID:32007143

9. Novel Coronavirus Pneumonia Emergency Response Epidemiology Team. [The epidemiological characteristics of an outbreak of 2019 novel coronavirus diseases (COVID-19) in China]. Zhonghua Liu Xing Bing Xue Za Zhi. 2020; 41:145-151.

https://doi.org/10.3760/cma.j.issn.0254-

6450.2020.02.003

PMID:32064853

10. Wang D, Hu B, Hu C, Zhu F, Liu X, Zhang J, Wang B, Xiang $\mathrm{H}$, Cheng $\mathrm{Z}$, Xiong $\mathrm{Y}$, Zhao $\mathrm{Y}$, Li $\mathrm{Y}$, Wang $\mathrm{X}$, Peng $\mathrm{Z}$. Clinical Characteristics of 138 Hospitalized Patients With 2019 Novel Coronavirus-Infected Pneumonia in Wuhan, China. JAMA. 2020. [Epub ahead of print].

https://doi.org/10.1001/jama.2020.1585

PMID:32031570

11. Bernheim $A$, Mei $X$, Huang $M$, Yang $Y$, Fayad ZA, Zhang N, Diao K, Lin B, Zhu X, Li K, Li S, Shan H, Jacobi A, Chung M. Chest CT Findings in Coronavirus Disease-19 (COVID-19): Relationship to Duration of Infection. Radiology. 2020; [Epub ahead of print]. https://doi.org/10.1148/radiol.2020200463 PMID:32077789

12. Pan Y, Guan H, Zhou S, Wang Y, Li Q, Zhu T, Hu Q, Xia L. Initial CT findings and temporal changes in patients with the novel coronavirus pneumonia (2019-nCoV): a study of 63 patients in Wuhan, China. Eur Radiol. 2020. [Epub ahead of print]. https://doi.org/10.1007/s00330-020-06731-x PMID:32055945

13. Kim H. Outbreak of novel coronavirus (COVID-19): what is the role of radiologists? Eur Radiol. 2020. [Epub ahead of print]. https://doi.org/10.1007/s00330-020-06748-2 PMID:32072255

14. Pan F, Ye T, Sun P, Gui S, Liang B, Li L, Zheng D, Wang J, Hesketh RL, Yang L, Zheng C. Time Course of Lung Changes On Chest CT During Recovery From 2019 Novel Coronavirus (COVID-19) Pneumonia. Radiology. 2020. [Epub ahead of print]. https://doi.org/10.1148/radiol.2020200370 PMID:32053470

15. Kanne JP, Chest CT. Chest CT Findings in 2019 Novel Coronavirus (2019-nCoV) Infections from Wuhan, China: Key Points for the Radiologist. Radiology. 2020; 295:16-17. https://doi.org/10.1148/radiol.2020200241 PMID:32017662 
16. Chung $M$, Bernheim A, Mei X, Zhang $N$, Huang $M$, Zeng X, Cui J, Xu W, Yang Y, Fayad ZA, Jacobi A, Li K, Li S, Shan H. CT Imaging Features of 2019 Novel Coronavirus (2019-nCoV). Radiology. 2020; 295:202-07.

https://doi.org/10.1148/radiol.2020200230

PMID:32017661

17. Wei M, Yuan J, Liu Y, Fu T, Yu X, Zhang ZJ. Novel Coronavirus Infection in Hospitalized Infants Under 1 Year of Age in China. JAMA. 2020. [Epub ahead of print].

https://doi.org/10.1001/jama.2020.2131

PMID: $\underline{2058570}$

18. Wang XF, Yuan J, Zheng YJ, Chen J, Bao YM, Wang YR, Wang LF, Li H, Zeng JX, Zhang YH, Liu YX, Liu L. [Retracted: clinical and epidemiological characteristics of 34 children with 2019 novel coronavirus infection in Shenzhen]. Zhonghua Er Ke Za Zhi. 2020; 58:E008.

https://doi.org/10.3760/cma.j.issn.0578-

1310.2020.0008

PMID:32062875

19. Dong Y, Mo X, Hu Y, Qi X, Jiang F, Jiang Z, Tong S. Epidemiological Characteristics of 2143 Pediatric Patients With 2019 Coronavirus Disease in China. Pediatrics. 2020. [Epub ahead of print].

https://doi.org/10.1542/peds.2020-0702

PMID:32179660

20. Wang W, Tang J, Wei F. Updated understanding of the outbreak of 2019 novel coronavirus (2019-nCoV) in Wuhan, China. J Med Virol. 2020; 92:441-47.

https://doi.org/10.1002/jmv.25689

PMID:31994742

21. Liu K, Fang YY, Deng Y, Liu W, Wang MF, Ma JP, Xiao W, Wang YN, Zhong MH, Li CH, Li GC, Liu HG. Clinical characteristics of novel coronavirus cases in tertiary hospitals in Hubei Province. Chin Med J (Engl). 2020. [Epub ahead of print]. https://doi.org/10.1097/CM9.0000000000000744 PMID:32044814

22. Zhou L, Liu HG. [Early detection and disease assessment of patients with novel coronavirus pneumonia]. Zhonghua Jie He He Hu Xi Za Zhi. 2020; 43:E003.

https://doi.org/10.3760/cma.j.issn.10010939.2020.0003

PMID: $\underline{32023686}$

23. Desforges M, Miletti TC, Gagnon M, Talbot PJ. Activation of human monocytes after infection by human coronavirus 229E. Virus Res. 2007; 130:228-40. https://doi.org/10.1016/j.virusres.2007.06.016 PMID:17669539

24. Yilla $M$, Harcourt $B H$, Hickman CJ, McGrew $M$, Tamin A, Goldsmith CS, Bellini WJ, Anderson $\sqcup$.
SARS-coronavirus replication in human peripheral monocytes/macrophages. Virus Res. 2005; 107:93-101. https://doi.org/10.1016/j.virusres.2004.09.004 PMID: 15567038

25. Collins AR. In vitro detection of apoptosis in monocytes/macrophages infected with human coronavirus. Clin Diagn Lab Immunol. 2002; 9:1392-95. https://doi.org/10.1128/cdli.9.6.1392-1395.2002 PMID: 12414783

26. Kohyama S, Ohno S, Suda T, Taneichi M, Yokoyama S, Mori M, Kobayashi A, Hayashi H, Uchida T, Matsui M. Efficient induction of cytotoxic $T$ lymphocytes specific for severe acute respiratory syndrome (SARS)associated coronavirus by immunization with surfacelinked liposomal peptides derived from a non-structural polyprotein 1a. Antiviral Res. 2009; 84:168-77. https://doi.org/10.1016/i.antiviral.2009.09.004 PMID:19748524

27. Ohno S, Kohyama S, Taneichi M, Moriya O, Hayashi $H$, Oda H, Mori M, Kobayashi A, Akatsuka T, Uchida T, Matsui M. Synthetic peptides coupled to the surface of liposomes effectively induce SARS coronavirus-specific cytotoxic T lymphocytes and viral clearance in HLAA*0201 transgenic mice. Vaccine. 2009; 27:3912-20. https://doi.org/10.1016/j.vaccine.2009.04.001 PMID:19490987

28. He Z, Zhao C, Dong Q, Zhuang H, Song S, Peng G, Dwyer DE. Effects of severe acute respiratory syndrome (SARS) coronavirus infection on peripheral blood lymphocytes and their subsets. Int J Infect Dis. 2005; 9:323-30.

https://doi.org/10.1016/j.ijid.2004.07.014

PMID:16095942

29. Chu H, Zhou J, Wong BH, Li C, Chan JF, Cheng ZS, Yang D, Wang D, Lee AC, Li C, Yeung ML, Cai JP, Chan IH, et al. Middle East Respiratory Syndrome Coronavirus Efficiently Infects Human Primary T Lymphocytes and Activates the Extrinsic and Intrinsic Apoptosis Pathways. J Infect Dis. 2016; 213:904-14. https://doi.org/10.1093/infdis/jiv380 PMID:26203058

30. National Health Commission of the People's Republic of China. Diagnosis and management program of novel coronavirus-infected pneumonia (4th edition). 2020. http://www.gov.cn/zhengce/zhengceku/20202001/2028/5472673/files/5472670f5472696c5472610 cc5472609d5472674d5472636a5472676f5472679a54 72679f5472670b5472642d5472972b.pdf

31. National Health Commission of the People's Republic of China. Diagnosis and management program of novel coronavirus pneumonia (6th edition). 2020.

http://www.nhc.gov.cn/yzygj/s7653p/202002/208334 a208326dd202094d202329df202351d202007da20200 8aefc202002/files/b202218cfeb202001bc254639af202 


\section{7f202922bf202006b202817.pdf}

32. Guo YH, Chen FY, Wang GS, Chen L, Gao W. Dietinduced hyperhomocysteinemia exacerbates vascular reverse remodeling of balloon-injured arteries in rat. Chin Med J (Engl). 2008; 121:2265-71. https://doi.org/10.1097/00029330-200811020-00011 PMID:19080331

33. Hofmann MA, Lalla E, Lu Y, Gleason MR, Wolf BM, Tanji N, Ferran LJ Jr, Kohl B, Rao V, Kisiel W, Stern DM, Schmidt AM. Hyperhomocysteinemia enhances vascular inflammation and accelerates atherosclerosis in a murine model. J Clin Invest. 2001; 107:675-83. https://doi.org/10.1172/JCl10588 PMID: 11254667

34. Jakubowski H. Pathophysiological consequences of homocysteine excess. J Nutr. 2006 (6 Suppl); 136:1741S-49S.

https://doi.org/10.1093/in/136.6.1741S

PMID:16702349

35. Deminice R, da Silva RP, Lamarre SG, Brown C, Furey GN, McCarter SA, Jordao AA, Kelly KB, King-Jones K, Jacobs RL, Brosnan ME, Brosnan JT. Creatine supplementation prevents the accumulation of fat in the livers of rats fed a high-fat diet. J Nutr. 2011; 141:1799-804.

https://doi.org/10.3945/jn.111.144857

PMID:21880953

36. Triant VA, Lee H, Hadigan C, Grinspoon SK. Increased acute myocardial infarction rates and cardiovascular risk factors among patients with human immunodeficiency virus disease. J Clin Endocrinol
Metab. 2007; 92:2506-12.

https://doi.org/10.1210/jc.2006-2190

PMID: 17456578

37. Wijekoon EP, Brosnan ME, Brosnan JT. Homocysteine metabolism in diabetes. Biochem Soc Trans. 2007; 35:1175-79. https://doi.org/10.1042/BST0351175 PMID:17956306

38. Abike F, Engin AB, Dunder I, Tapisiz OL, Aslan C, Kutluay L. Human papilloma virus persistence and neopterin, folate and homocysteine levels in cervical dysplasias. Arch Gynecol Obstet. 2011; 284:209-14. https://doi.org/10.1007/s00404-010-1650-7 PMID:20740364

39. Deminice R, Silva TC, de Oliveira VH. Elevated homocysteine levels in human immunodeficiency virus-infected patients under antiretroviral therapy: A meta-analysis. World J Virol. 2015; 4:147-55.

https://doi.org/10.5501/wjv.v4.i2.147 PMID:25964880

40. Roblin X, Pofelski J, Zarski JP. [Steatosis, chronic hepatitis virus $\mathrm{C}$ infection and homocysteine]. Gastroenterol Clin Biol. 2007; 31:415-20. https://doi.org/10.1016/S0399-8320(07)89402-4 PMID: 17483780

41. Lopez-Raton M, Rodriguez-Alvarez MX, Suarez CC, Sampedro FG. OptimalCutpoints: An R Package for Selecting Optimal Cutpoints in Diagnostic Tests. J Stat Softw. 2014; 61:1-36.

https://doi.org/10.18637/jss.v061.i08 